\title{
Effectiveness of oral health education on knowledge and practice among 15 year old children of Government High Schools in Lucknow City (Uttar Pradesh).
}

\begin{abstract}
:
Background: Oral health education, as a part of oral health promotion, has been considered as essential and basic part of dental health services.School provides a perfect setting for health education programmes aiming to control the growing burden of oral diseases and to promote oral health. Aim: To determine the impact of oral health education on oral health knowledge and practice among 15 year old school going children of government high schools in Lucknow city. Design: The schools were selected by simple random sampling method following the lottery method of selection. These classes have children of 15 years of age. Each class has two to three sections, and these sections were chosen for the purpose of data collection. Children were selected by simple random sampling technique.

Results: The oral health knowledge and awareness of all children improved significantly after the education. Statistically significant increase in the proportion of correct responses was noted following the programme especially in relation to Q2, Q6, Q7, Q9 and Q10. Conclusion: The information, which children receive and the awareness that is created during the programme in school, contributes to the first tentative steps to forming their attitudes and beliefs, which may later lead to healthier choices.
\end{abstract}

Key words: Health, Education, School, Children, Awareness, Knowledge.

\section{Introduction:}

Oral health is an important part of general health. A healthy mouth and dentition not only allows a person to enjoy food, speak properly and have social confidence, it is also a reflection of general health. It is a part of everyday living and is an essential dimension to the quality of life.[1] However; millions of individuals suffer from dental caries and periodontal diseases.[2]

Oral health education, as a part of oral health promotion, has been considered as essential and basic part of dental health services.[3] It is defined as "a process that informs, motivates, and helps persons to adopt and maintain healthy practices and lifestyles; advocates environmental changes as needed to facilitate this goal; and conducts professional training and research to the same end."[4]

\begin{tabular}{|l|l|}
\hline \multicolumn{3}{|c|}{ Access this article online } \\
\hline \multirow{2}{*}{$\begin{array}{l}\text { Website: } \\
\text { www.ujds.in }\end{array}$} & Quick Response Code \\
\hline $\begin{array}{l}\text { DOI: } \\
\text { https://doi.org/10.21276/10.21276/ujds.2020.6.2.4 }\end{array}$ & \\
\hline
\end{tabular}

School provides a perfect setting for health education programmes aiming to control the growing burden of oral diseases and to promote oral health. School children are considered to be an important target group for various health education activities with the underlying objective of inculcating healthy life style practices to last for lifetime.[2] The school based dental health education can bring comprehensive dental care including preventive measures to school children where they are gathered anyway for nondental reasons in the largest possible numbers. This is

\section{${ }^{1}$ MALHOTRA S, ${ }^{2}$ SINGH $\mathbf{P}_{\boldsymbol{r}}{ }^{3}$ DUBEY $\mathrm{H}$. \\ ${ }^{1}$ Public Health Dentistry, Career Post Graduate Institute of Dental Sciences. ${ }^{2}$ Public Health Dentistry, Sarsawati Dental College, Lucknow. ${ }^{3}$ Periodontics, Saraswati Dental College, Lucknow}

Address for Correspondence: Dr. Pallavi Singh Q-501, Celebrity Meadows, Sushant Golf City, Ansal Api, Lucknow-226002

E-mail: pallavirolisingh@gmail.com

Received : 14 July 2020, Published : 31 August 2020

How to cite this article: Malhotra, S., Singh, P., \& Dubey, H. (2020). Effectiveness of Oral Health Education on knowledge and practice among 15 year old children of Government High Schools in Lucknow city (Uttar Pradesh). UNIVERSITY JOURNAL OF DENTALSCIENCES, 6(2): 51-6. 
particularly advantageous in dentist-deprived areas.[5] It is an economical and powerful means of raising the community health of future generations.[6] A combination of educational and health facilities is sensible both ideologically and logistically.[5]

Therefore, the present study would attempt to assess the effectiveness of oral health education on the oral health knowledge and Practice among 15 year old children of Government high schools in Lucknow city.

\section{Materials and Methods:}

The present study was conducted to assess the effectiveness of oral health education on the oral health knowledge and practice among 15 year old school going children of government high schools in Lucknow City. List of government high schools located within the Lucknow municipality was obtained from District School Officer (DSO), Chowk, Lucknow.

The schools were selected by simple random sampling method following the lottery method of selection. The ratio was maintained while selecting the samples from different areas. In every school, the classes of $8^{\text {th }}$ and $9^{\text {th }}$ were chosen. These classes have children of 15 years of age. Children were selected by simple random sampling technique. All children present in the selected schools were selected as a sample. Pilot study was conducted on 50 subjects using a preformed proforma with power analysis 0.8 . Ethical clearance was obtained from the ethical clearance committee.

Inclusion criteria were children who had completed 15 years or running in $15^{\text {th }}$ year of life on the date of the examination, children who were willing to participate and who were present on the day of the study. Exclusion criteria were children who were undergoing orthodontic treatment and were having crowding/overlapping of teeth.

Before the start of the survey, the guide calibrated the investigator in the Department of Public Health Dentistry. The recorder in the study was also trained in the same department regarding the contents of the proforma and the method of recording.

The proforma consisted of two parts. First part consisted of recording general information including name, age, gender, and oral hygiene practices, and the questionnaire. Second part consisted of Plaque index and Gingival index.
At the beginning of the study, a structured close-ended questionnaire prepared to assess the oral health knowledge and practice was distributed to all the students. Questions were explained briefly to the students by the examiner. After the sufficient time, questionnaire was collected back and checked out. A score of one was assigned for every correct answer. Clinical examination was carried out in classrooms or library under natural day light. Subjects were asked to sit comfortably on a chair. They were examined for plaque status and gingival status by using Silness and Loe Plaque index, and Loe and Silness Gingival index.[5] After collecting the base line data, a brief oral health education on a range of topics related to oral health was given to the study subjects. A reinforcement of oral health education regarding proper oral hygiene technique and its importance in maintaining good oral health was carried out after one week of examination.

At the end of four weeks, same questionnaire regarding oral health knowledge and practice distributed to the children. Sufficient time was given to answer them and was collected back and checked out for completion. Later same methodology of examination was followed to determine gingival and plaque scores of the children as that of baseline.

Adequate numbers of instruments were carried to the site of examination, so as to avoid disturbances. The instruments were used once and were autoclaved in the Department of Public Health Dentistry next day for reuse. Any specific clinical or pathological condition requiring immediate attention was brought to the notice of the teacher or parent and was advised to be consulted with specialist immediately. The data obtained were statistically analyzed using Statistical Package For Social Sciences (SPSS 11.0) and Systat 8.0; and Microsoft word excel is used to generate tables, graphs etc.

\section{Results:}

Out of 600,587 children were selected in the study as they were present during all the visits in the study. The age of all children ranged from 14-15 years with mean ( \pm SD) $14.91 \pm$ $0.29 \mathrm{yrs}$. The study subjects were mostly males $(57.6 \%)$. They used to clean their teeth once daily $(86.0 \%)$ with toothbrush (97.6\%), and toothpaste (93.2\%).

Pre-education the children had good oral health knowledge and awareness about number of teeth we have (79.0\%), permanent teeth lasts for $(57.4 \%)$, most important function of our teeth (73.6\%), what will happen if we don't care our teeth $(81.3 \%)$ and the effect of bleeding from gums (84.2\%). 
University J Dent Scie 2020; Vol. 6, Issue 2

However, children had poor oral health knowledge and awareness about sets of teeth we have in our life (63.4\%), things that harm our teeth the most $(73.4 \%)$, when to brush the teeth $(86.7 \%)$, how often to visit the dentist (93.5\%) and ideal ways of keeping teeth healthy $(81.4 \%)$.

Post-education oral health knowledge and practice of study population are summarized graphically in Fig. 1.
Fig.1 Post-education oral health knowledge and awareness among study population.

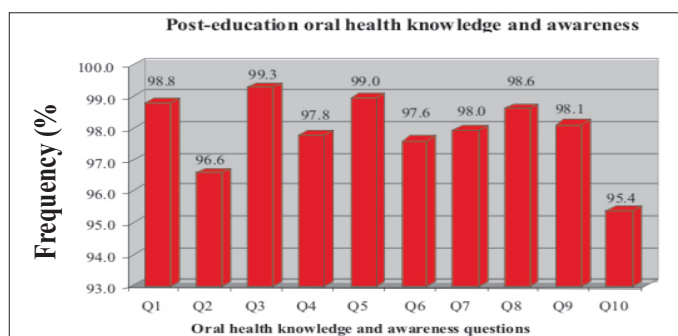

The pre and post oral health knowledge and awareness of study population children both showed that the oral health knowledge and awareness of all children improved significantly after the education. Statistically significant increase in the proportion of correct responses was noted following the programme especially in relation to Q2, Q6, Q7, Q9 and Q10. (Table 1)

\begin{tabular}{|c|c|c|c|c|c|}
\hline Question & $\begin{array}{c}\text { Pre education } \\
\text { oral health } \\
\text { knowledge and } \\
\text { awareness } \\
(n=587)(\%)\end{array}$ & $\begin{array}{c}\text { Post } \\
\text { education } \\
\text { oral health } \\
\text { knowledge } \\
\text { and } \\
\text { aw areness } \\
(n=587)(\%)\end{array}$ & $\begin{array}{l}\text { Improv ement } \\
\text { in oral health } \\
\text { knowledge } \\
\text { and awareness } \\
\text { (n) }(\%)\end{array}$ & $\begin{array}{l}\chi^{2} \text { value } \\
(\mathrm{DF}=1)\end{array}$ & p value \\
\hline How may teeth we have? & $464(79.0 \%)$ & $580(98.8 \%)$ & $116(19.8 \%)$ & 116.40 & - \\
\hline $\begin{array}{l}\text { How may sets of teeth we have in our } \\
\text { life time? }\end{array}$ & $215(36.6 \%)$ & $567(96.6 \%)$ & $352(60.0 \%)$ & 474.50 & $<0.001$ \\
\hline Our permanent teeth last for? & $337(57.4 \%)$ & $583(99.3 \%)$ & $246(41.9 \%)$ & 304.00 & - \\
\hline $\begin{array}{l}\text { What is the most important function of } \\
\text { our teeth? }\end{array}$ & $432(73.6 \%)$ & $574(97.8 \%)$ & $142(24.2 \%)$ & 140.10 & - \\
\hline $\begin{array}{l}\text { What happen, if we don't take care of } \\
\text { our teeth? }\end{array}$ & $477(81.3 \%)$ & $581(99.0 \%)$ & $104(17.7 \%)$ & 103.50 & - \\
\hline $\begin{array}{l}\text { Things that will cause most of the harm } \\
\text { to our teeth? }\end{array}$ & $156(26.6 \%)$ & $573(97.6 \%)$ & $417(71.0 \%)$ & 629.30 & $<0.001$ \\
\hline When you brush your teeth? & $78(13.3 \%)$ & $575(98.0 \%)$ & $497(84.7 \%)$ & 852.40 & $<0.001$ \\
\hline $\begin{array}{l}\text { Is bleeding from gums good/bad for } \\
\text { health? }\end{array}$ & $494(84.2 \%)$ & $579(98.6 \%)$ & $85(14.5 \%)$ & 78.27 & - \\
\hline How often you visit your dentist? & $38(6.5 \%)$ & $576(98.1 \%)$ & $538(91.7 \%)$ & 988.30 & $<0.001$ \\
\hline \multicolumn{6}{|l|}{$\begin{array}{l}\text { What are the ideal ways of keeping } \\
\text { teeth healthy? }\end{array}$} \\
\hline & $109(18.6 \%)$ & $560(95.4 \%)$ & $451(76.8 \%)$ & 706.80 & $<0.001$ \\
\hline Total & $\begin{array}{c}2800 \\
(47.7 \%)\end{array}$ & $5724(97.5 \%)$ & $2924(49.8 \%)$ & 3662.00 & $<0.001$ \\
\hline
\end{tabular}

Table 1: Pre and post education oral health knowledge and awareness of the study population children 
University J Dent Scie 2020; Vol. 6, Issue 2

The Plaque status and Gingival status (PI and GI) of the study population was decreased (i.e. status was improved) significantly $(\mathrm{p}<0.001)$ after the oral health education programme. The pre and post education Plaque status and Gingival status (PI and GI) of the study population are summarized in Table 2

\begin{tabular}{|c|c|c|c|c|c|}
\hline Parameters & Pre education & $\begin{array}{c}\text { Post } \\
\text { education }\end{array}$ & $\begin{array}{c}\text { Change } \\
\mathbf{( \% )}\end{array}$ & $\begin{array}{c}\text { t value } \\
\mathbf{( D F}=586)\end{array}$ & $\begin{array}{c}\mathbf{p} \\
\text { value }\end{array}$ \\
\hline PI score & $1.75 \pm 0.23$ & $1.40 \pm 0.12$ & $19.7 \%$ & 6.66 & $<0.001$ \\
\hline GI score & $1.28 \pm 0.19$ & $0.93 \pm 0.12$ & $27.3 \%$ & 8.70 & $<0.001$ \\
\hline
\end{tabular}

Table 2: Pre and post education plaque and gingival status (Mean $\pm \mathrm{SD}, \mathrm{n}=587$ ) of the study population.

Further, the gender wise mean Plaque Index and Gingival Index scores of studied children are summarized in Tables 3 and 4.

\begin{tabular}{|c|c|c|c|c|c|}
\hline Variables & Pre- education & Post- education & $\begin{array}{c}\text { Mean change } \\
\text { (pre to post) }\end{array}$ & $\begin{array}{c}\mathbf{t} \\
\text { value }\end{array}$ & $\begin{array}{c}\mathbf{p} \\
\text { value }\end{array}$ \\
\hline Males & $1.70 \pm 0.22$ & $1.39 \pm 0.13$ & $0.31 \pm 0.27$ & 5.43 & $\mathrm{p}<0.001$ \\
\hline Females & $1.98 \pm 0.15$ & $1.48 \pm 0.10$ & $0.50 \pm 0.16$ & 6.12 & $\mathrm{p}<0.001$ \\
\hline
\end{tabular}

Table 3: PI levels (Mean \pm SD) of two genders

\begin{tabular}{|c|c|c|c|c|c|}
\hline Variables & $\begin{array}{c}\text { Pre- } \\
\text { education }\end{array}$ & $\begin{array}{c}\text { Post- } \\
\text { education }\end{array}$ & $\begin{array}{c}\text { Mean change } \\
\text { (pre to post) }\end{array}$ & $\begin{array}{c}\mathbf{t} \\
\text { value }\end{array}$ & $\begin{array}{c}\text { P } \\
\text { value }\end{array}$ \\
\hline Males & $1.24 \pm 0.19$ & $0.91 \pm 0.12$ & $0.33 \pm 0.20$ & 7.51 & $\mathrm{p}<0.001$ \\
\hline Females & $1.48 \pm 0.10$ & $1.03 \pm 0.10$ & $0.45 \pm 0.17$ & 5.20 & $\mathrm{p}<0.001$ \\
\hline
\end{tabular}

Table 4: GI levels (Mean $\pm \mathrm{SD}$ ) of two genders

\section{Discussion:}

The role of prevention in dental health in India is a challenge to all dental health professionals. The only practical solution that is worth heading for would be primary prevention wherein the problem is struck at the root, that is, even before its inception. Primary prevention includes health promotion by way of health education. Health education can be delivered by either personal instruction or by the use of self-instruction manuals and audiovisual aids. Several other methods can also be employed to deliver effective health education. ${ }^{7}$ Therefore, the present study was conducted with an aim to assess the effectiveness of oral health education on the oral health knowledge and practice among 15 year old children of Government high schools in Lucknow city. Moreover, oral health behavior is a result of a lifelong learning process; this process can best be achieved by an interdisciplinary collaboration among dentists and professionals in other areas, such as psychologists and teachers. [8]

A number of systematic reviews have shown that oral health education can be effective in increasing knowledge in short term, and to some extent, behaviour such as tooth brushing and healthy eating habits. $[9,10]$ 
This study demonstrates that a school-based, easy to organize, inexpensive educational intervention was effective in improving knowledge and awareness of the children. This is in accordance with the findings of Helderman V.N (1997)[11], Worthington H.V (2001)[12], Biesbrock A.R (2003)[13], Chapman A. (2006)[14] and Prabhu R (2006)[15]. At baseline, reasons for the poor level of oral hygiene among students may be that no school based oral health education programmes are available, and no regular dental examinations are provided to them.

Regarding the evaluation of the questionnaire, a greater percentage of questions were answered correctly following the educational programme. Statistical significant increase in the proportion of correct responses was noted following the programme especially in relation to Q2, Q6, Q7, Q9, and Q10. This determines that the subjects increased knowledge and awareness with respect to number of sets of teeth, thing that our teeth the most, frequency of brushing, optimum frequency to dental visits, and ideal ways for keeping teeth healthy. Similar results were seen in studies conducted by Schou L. (1985) ${ }^{16}$ and Goel P. (2005)[17].

Oral health education has been demonstrated to have a positive impact in lowering plaque and gingival indices score in this cohort. The majority of reduction have been on the order of $30 \%$ independent of setting on target group following educational programme.[14] In the present study, there were $19.7 \%$ reduction in the plaque score and $27.3 \%$ reduction in gingival score of the subjects following the educational programme. But in the Biesbrock study[13], there was 51\% reduction in gingival score and $29 \%$ reduction in plaque score. This was because of the learning process which was accomplished through small groups of four to fifteen members.

In the present study, a significant reduction of plaque and gingival scores following the programme was found in male as well as in female study subjects. In contrast to our findings, Ajithkrishnan C.G et al. (2010)[18] found that females showed significant improvement in their oral health status. This may be due to the fact that females are seemed to be more enthusiastic and more concerned regarding their personal hygiene and health care.

\section{Conclusion :}

This research concerning the outcome of oral health education programme on oral health has shown favorable results. The information, which children receive and the awareness that is created during the programme in school, contributes to the first tentative steps to forming their attitudes and beliefs, which may later lead to healthier choices. Thus an attempt has to been made to enhance children's knowledge and awareness about oral health. It would do us a world of good to remember the inspiring words of Swami Vivekananda:

"Arise, awake and stop not till the goal is reached".

\section{Important to paediatric dentists:}

- Early oral health education intervention should be implemented in all schools as it can bring about change in oral health related behavior and dentist will be in direct contact with the children.

- Reinforcements of the oral health education programs might lead to better results and there will be positive footfall of patients to dentist.

- Teachers can act as oral health educators if trained properly and if any dental emergency arises can contact to nearby dentist

\section{References:}

1. Gupta G., Rao G.N, Saha S. Oral health knowledge, attitude and practice amongst nursing students in Lucknow city. Journal of the Indian Association of Public Health Dentistry 2008; 12:40-44.

2. Ganesh S.A, Bhat P.K, Jyothi C. Initial impact of health education program on oral health, knowledge and awareness among 15-yearoldchildren of government high school, Sarakki, Bangalore. Journal of The Indian Associationof Public Health Dentistry 2007; 10:57-65.

3. Yazdani R, Miira M.V, Nouri M, Murtomma H. School-based education to improve oral cleanliness and gingival health in adolescents in Tehran, Iran.International Journal Of Pediatric Dentistry 2009; 19:274-281.

4. Hiremath S.S. Textbook of Preventive and Community Dentistry, $2^{\text {nd }}$ Edition 2011, Elsevier Publications.

5. Peter S. Essentials of Preventive And Community Dentistry, $2^{\text {nd }}$ Edition 2005, Arya Publications: 582.

6. Dileep C.L, Basavaraj P., Jayaprakash K. A survey on knowledge, attitude, and practice about oral hygiene among teachers in Kanpur city. Journal Of The Indian Association Of Public Health Dentistry 2006; 8:57-59.

7. Hebbal M. et al. evaluation of knowledge and plaque scores in school children before and after health education. Dent Res j, 2011 OctDec;8(4): 189-196.

8. Farias I.A et al.A Health Education Program for Brazilian Public school children: the effect on dental health practice and oral health awareness. Journal of Public Health Dentistry, 2009; vol. 69(4):225230 .

9. Wendt L.K et al. Early dental caries risk assessment and prevention in pre-school children. Acta Odontol Scand, 2001;59(5):261-6.

10. Kay E.J and Locker D. "Is dental health educatio effective? A systematic review of current evidence". Community Dent Oral Epidemiol 1996; 24: 231-5

11. Helderman V.N etal. Effect evaluation of an oral health education programme in primary schools in Tanzania. Community Health and oral Epidemiology,1997, vol.25:296-300. 
University J Dent Scie 2020; Vol. 6, Issue 2

12. Worthington H.V et al. A cluster randomized controlled trial of a dental health education programme for 10 year old children. Journal of Public Health Dentistry, 2001; 61 (1): 22-27.

13. Biesbrock A.R etal. Initial impact of a national dental education program on oral health and dental knowledge of children. The journal of Contemporary Dental Practice, 2003;4(2): 1-7.

14. Chapman A. et al. An oral health education programme based on the National Curriculum. International Journal of Paediatric Dentistry, 2006; 16: 40-44.

15. Prabhu R. Effect of dental health education on dental attendance of 8-9 year old school children belonging to low socioeconomic status. Karnataka state Dental Journal, 2006; 25(1): 10-14.

16. Shou L. Active involvement principle in dental health education. Community Health and Oral Epidemiology, 1985;18: 128-132.

17. Goel P. et al. Evaluating the effectiveness of school based dental health education programme among children of different socio-economic groups. J Indian Soc Pedo Preventive Dent, 20059: 131-33.

18. Ajithkrishnan CG et al. Impact of oral health education on oral health of 12 and 15 year old school children of Vadodara city, Gujarat State. JIOH, October 2010, Volume 2 (Issue 3):15-20. 